\title{
Lifestyle issues in children and adolescents with chronic inflammatory bowel diseases
}

\author{
P SHERMAN, MD, FRCPC, A GRIFFITHS, MD, FRCPC, M MARCON, MD, FRCPC, \\ C SMITH, RN, R GEIST, MD, FRCPC
}

\begin{abstract}
The goals of therapy in chronic inflammatory bowel diseases in pediatrics include decreasing mucosal inflammation, the restoration of optimal growth and pubertal development, and the return to a normal, age-appropriate lifestyle. The latter is best served by minimizing restrictions; for example, school attendance, extracurricular activities, travel and the child's interactions with both siblings and peers. In most instances dietary restrictions are also inappropriate and may prove detrimental. Children and adolescents are not simply 'little adults'. Teenagers dread being perceived as different from their peers. They are especially bothered therefore by cosmetic side effects associated with corticosteroid therapy and by impaired growth and pubertal development. Although not discussed openly, many adolescents are also concerned about their subsequent ability to have children and the potential for future development of neoplasms. The great majority of affected children adapt and function very well. Psychosocial factors, although clearly not the cause of inflammatory bowel diseases, are operative in many subsets of children with less than optimal function in daily activities. Children at particular risk are those with premorbid low self-esteem, dysfunction in family dynamics, or severe growth failure. Intervention and support provided through psychiatric and medical social work consultations and by the involvement of self-help groups are often key determinants for restoration of a normal lifestyle. Information about the underlying chronic disease, when provided at a level that is appropriate for age and cognitive function, can decrease anxiety and fears by reducing uncertainty and promoting a feeling of control. Can J Gastroenterol 1990;4(7):364-368 (pour résumé, voir page 365)
\end{abstract}

Key Words: Crohn's disease, Dietary, Intestine, Psychosocial, Ulcerative colitis

The Hospital for Sick Children, Toronto, Ontario

Correspondence and reprints: Dr P Sherman, Room 1448, The Hospital for Sick Children, 555 University Avenue, Toronto, Ontario M5G 1 X8. Telephone (416) 598-6185
$\mathrm{C}$ ROHN'S DISEASE AND IDIOPATHIC ulcerative colitis are chronic in. flammatory diseases of the bowel of un. known etiology. They are both charac. terized by a remitting and relapsing clinical course. Goals of medical therapy are summarized in Table 1. One of the goals is to control the severity of mucosal inflammation and thereby alleviate clinical symptoms. Secondly, in pediatric chronic inflam. matory bowel disease (IBD) it is important to optimize growth and pubertal development. Intestinal inflammation frequently results in anorexia and sig. nificantly decreased caloric intake. As

\section{TABLE 1 \\ Goals of medical therapy in pediatric chronic inflammatory bowel diseases \\ Decrease mucosal inflammation \\ Alleviate clinical symptoms \\ Optimize growth velocity (especially height) \\ Normalize onset and stages of pubertal development \\ Return the child to a normal lifestyle}




\section{Questions liées au mode de vie de l'enfant et de l'adolescent atteints d'entéropathies inflammatoires chroniques}

RESUME: Le traitement des maladies inflammatoires de l'intestin en milieu pédiatrique a pour objectifs de réduire l'inflammation de la muqueuse, de restaurer la croissance optimale et le développement pubertaire, et de permettre le retour à un mode de vie normal, adapté à l'âge du patient. C'est en minimisant les restrictions relatives à la fréquentation de l'école, aux activités extracurriculaires, aux voyages et aux interactions de l'enfant avec ses frères et soeurs et ses pairs, que l'on parvient le mieux à réaliser ce dernier but. Dans la plupart des cas, les restrictions alimentaires sont elles aussi inappropriées et peuvent s'avérer nocives. Enfants et adolescents ne sont pas simplement de "petits adultes". Terrifiés à l'idée d'être rejetés par leurs pairs, les adolescents sont tout particulièrement sensibles aux effets secondaires cosmétiques de la corticothérapie, au retard de croissance et de développement pubertaire. Sans en parler ouvertement, de nombreux adolescents s'interrogent aussi sur leur future capacité de fonder une famille et sur le développement éventuel de néoplasmes. La grande majorité des enfants s'adaptent et fonctionnent très bien. Les facteurs psychosociaux, quoique ne constituant évidemment pas la cause des MII, interviennent dans de nombreux sous-groupes d'enfants qui éprouvent des difficultés dans leurs activités quotidiennes. Les patients particulièrement vulnérables sont les enfants qui avaient déjà des problèmes d'estime de soi avant la maladie, ceux dont le milieu familial est perturbé ou qui sont atteints d'un sévère retard de croissance. L'intervention et l'appui des professionnels oeuvrant en psychiatrie et en médecine sociale, ainsi que l'appartenance à un groupe de soutien sont souvent essentiels à la reprise d'un mode de vie normal. Quand ils sont offerts à un niveau adapté à l'âge et à la fonction cognitive, les renseignements concernant la maladie chronique sous-jacente peuvent réduire l'anxiété et les craintes de l'enfant; ils diminuent son incertitude et lui donnent un sens de contrôle accru.

a result, up to one-third of adolescents with Crohn's disease and $10 \%$ of those with ulcerative colitis will present with medical and psychological complications of decreased growth velocity and delayed onset of puberty (1). In spite of the fact that currently available drug therapy cannot eradicate the underlying disease, it is essential to return affected children and adolescents to a normal lifestyle which is appropriate for chronological age and cultural background.

\section{STRIVING TO NORMALIZE LIFESTYLE}

For many children with IBD, alleviation of clinical symptoms will result in a rapid return to premorbid daily activities. It is the authors' experience, however, that in a subset of affected patients this does not occur despite control of mucosal inflammation. Misconceptions about the role of stress in the etiology of the underlying disease increases parental guilt and anxiety which may then decrease parenting capacity. Secondary gain for the affected child can also promote limitations in the day-to-day function of patients. External restrictions all too frequently compound the problem. Therefore, in the vast majority of situations, the authors strongly encourage the lifting of both physician and parental imposed restrictions brought about as a result of diagnosis of a chronic disease such as Crohn's disease or idiopathic ulcerative colitis (Table 2).

Except in the most exceptional circumstances, education by a home tutor is discouraged. Although a tutor can provide excellent educational resources, this approach deprives the child or adolescent of the important social and extracurricular aspects of daily interactions at school with members of their peer group. Using similar logic, travel plans for families should be executed without undue consideration of their affected child. In the majority of nonemergent clinical settings, specific therapy can be adjusted to holiday plans and contact with a consultant pediatric gastroenterologist can be organized as required. Most patients
TABLE 2

Methods to obtain a normal lifestyle for pediatric patients with chronic inflammatory bowel diseases

Promote regular school attendance Encourage full participation in extracurricular activities

Allow travel

Eliminate unnecessary dietary restrictions

should be allowed to participate fully in both casual and organized sporting activities.

The merits and necessity of dietary restrictions also need to be critically examined in children and adolescents. Physicians may recommend diets that are restricted in refined sugars, lactose and dietary fibre as part of the overall treatment regimen. In addition, parents often have the impression that the underlying disease is either caused or exacerbated by specific dietary constituents. A major problem with dietary modifications is that they frequently result in a less appetizing diet which discourages total caloric intake. Levenstein et al (2) concluded that "lifting of dietary restrictions, which results in a more appetizing and nutritious diet, does not cause symptomatic deterioration or precipitate intestinal obstruction in Crohn's disease." Unrelated to IBD, some patients may have genetic hypolactasia and dietary lactose intolerance. Although limitations of lactose intake may provide some relief of intestinal symptoms, there is no strong evidence that it alters underlying disease activity.

Imposition of dietary modifications can result in a major source of conflict between the children and both parents and unaffected siblings. Dietary modifications also highlight differences between patients and their peer group. Therefore, except in specific circumstances (ie, salt restriction while on oral corticosteroids, an initial course of elemental feedings, or partial bowel obstruction due to stricture formation), a full diet for age is most appropriate. Other commentators feel differently, however, and recommend modification of lifestyle to a regulated daily routine, particularly related to meals, as part of the treatment program (3). 
The present authors have recently provided epidemiological evidence that infant feeding practices might have a role in the later development of Crohn's disease in childhood (4). In this study mothers were used as the source of information to reduce recall bias and nonaffected siblings were employed as controls to account for potential genetic and environmental factors as confounding variables. Multivariate analysis revealed that both an absence of breast feeding (adjusted relative risk 3.6; $95 \%$ confidence intervals 1.4 to $9.0 ; \mathrm{P}<0.01)$ and episodes of diarrhea during infancy $(2.7 ; 1.5$ to 5.8 ; $\mathrm{P}<0.02$ ) were associated with an increased likelihood of later Crohn's disease. Although epidemiologic studies such as this provide evidence of an association, they do not prove cause and effect (5). Moreover, although a previous study in adults is in agreement with the authors' findings (6), two other studies did not provide similar results $(7,8)$. Therefore, until confirmed by additional data this observation does not yet justify any modification of infant feeding practices among farîlies whose children are potentially at increased risk for the development of IBD.

\section{SPECIFIC CONCERNS OF CHILDREN}

The particular worries that affect individual patients are, as among adults, highly individualized. Nevertheless, some general concerns are particularly relevant to the pediatric population (Table 3). For example, adolescence is a stage in life when body image is a major psychological issue. Delays in growth and pubertal development can, therefore, be sources of major emotional turmoil for affected patients. Similarly, complications of the underlying disease (such as perianal and rectovaginal fistulas) and the future possibility of an abdominal incision scar and ileostomy are often major concerns for adolescents (9). Medical therapy can also result in altered body composition and strongly influence concepts about body image. The cosmetic side effects of oral corticosteroids are a powerful disincentive for many adoles- cents to consider even a short term course of prednisone therapy.

Both school-aged children and teenagers are strongly influenced by their peer groups. They desire to fit in with the group because the penalties of being perceived as different are emotionally devastating. Therefore, a major concern for pediatric patients with IBD is how the chronic bowel disease will result in their being perceived as different from their peer group (10). This issue must be considered when one is advising patients and their parents about who should know about the underlying disease. Many teachers, coaches and camp instructors are frightened and exceptionally ill informed about the meaning and implications of chronic IBD for an affected child. Similar concerns relate to the discussion of IBD among peers and the parents of peers. Therefore, the relative merits of disclosure of the disease must often be discussed and decided on an individual basis. In general,the authors support the right to privacy and encourage disclosure only when it is medically indicated and strongly supported by the patient. For example, it may be most appropriate for the school nurse to be informed about the diagnosis and current therapy. The important, but broader, objective of educating teachers and the general public rests with health care professionals and with organizations such as the Canadian Foundation for Ileitis and Colitis rather than with individual children and their immediate family members.

Many adolescents and even children at much younger ages often have concerns about issues that neither their parents nor physicians wish to discuss openly. The authors are impressed by how many pediatric patients with IBD are concerned about the ability to have children in their adult years. As a result, they will often discuss this even if it has not been specifically raised.

Concerns about the potential for malignancy also plague many schoolaged children and adolescents even though the issue may not be brought up for discussion with physicians. When the concern is raised, relative risks for ulcerative colitis and Crohn's disease as
TABLE 3

Specific concerns of children and adolescents with chronic inflammatory bowel disease

Altered body image

Delayed growth and pubertal development

Cosmetic side effects of drug therapy Surgical incision scars

Stomas

Fistulas, perianal disease

Different from their peer group

'Hidden' concerns

Future fertility

Risk of neoplasms

they are currently understood must be discussed frankly. The authors recom. mend that this discussion take place with one, or preferably both, parents in attendance. On the other hand, whena child is functioning well in daily ac. tivities and concerns about future malignancy are not raised explicitly, the discussion may appropriately be delayed to a later date. With social dys. function this issue may, however, need to be addressed directly.

\section{PSYCHOLOGICAL FACTORS AFFECTING PEDIATRIC PATIENTS WITH IBD}

The vast majority of children with IBD function extremely well and rapid. ly return to a pre-morbid, age-ap. propriate lifestyle $(1,11,12)$. Howevet, a proportion will have intractable symptoms that require further surgical intervention or repeated hospitalization for more intensive medical therapy. In the authors' experience there is another subgroup of pediatric patients who appear to have relatively mild disease activity and clinical symptoms and no evidence of com. plications of the underlying disease and yet function extremely poorly in daily activities. This subset of patients appears to have psychological factors which impact negatively on their ability to resume a normal lifestyle. Al. though psychosocial factors clearly do not cause IBD, they may play a sig. nificant role in the clinical course of some patients $(13,14)$. Self-esteem and pre-morbid personality profile may in. fluence clinical outcome Children who are dependent on the 
opinion of others to maintain self-esteem are especially vulnerable (16). These children can view chronic intestinal disease as further evidence of their personal inadequacies which result in excessive withdrawal, regression and failure to meet developmental tasks. For these individuals and their families the multiple stresses related to a chronic disease must be addressed. For example, physical symptoms including abdominal pain can increase with anxiety. The coping ability of children with IBD often reflects parental adjustment and anxieties. Individual and more frequently in the pediatric population - family counselling and support provided by able psychiatric and medical social work consultations frequently prove extremely valuable $(13,17)$. These support services can play a key role in the restoration of family dynamics and the return of functionally disabled patients to a normal lifestyle.

For many patients with IBD, uncertainty and fears about the future can provide additional sources of considerable psychological stress. Based upon current experience in both children $(1,11,12)$ and adults $(18,19)$, an optimistic and reassuring outlook can be realistically outlined. Factual information provided at a level appropriate to cognitive function and maturity can reduce these anxieties and fears by reducing uncertainty and promoting a feeling of control (20). For children and adolescents a feeling of control is an adaptive mechanism that successfully controls powerful emotions and feelings (13). When patients (of any age) assume more control over their chronic illness there are reductions in anxiety and feelings of helplessness which, if left unchecked, can be associated with poor coping ability. Asking specific questions of the child, rather than gathering all medical information through his or her parents, is one simple method that allows the pediatric patient a measure of control over his or her illness. In an adaptive setting, extensive and detailed explanations about IBD, its treatment and potential complications are unlikely to be beneficial for children and young adolescents.
In this circumstance discussions focused primarily with the parents of the patient are appropriate. As the child matures they should, however, become more and more active in interactions with the health care providers.

Self-help groups such as the Canadian Foundation for Ileitis and Colitis provide educational pamphlets, books, videocassettes and symposiums which often prove beneficial (21). However, most of the available materials and presentations are not completely suitable for younger children and immature adolescents. A presentation of a range of possible complications, even if they are in reality extremely uncommon, has the potential to increase psychological stress and anxiety rather than provide reassurance.

\section{PARENTS AND THE FAMILY UNIT}

One of the special aspects of medical care provision to children and adolescents is the important interactions with both the patient and his or her parents. The emotional toll on parents cannot be underestimated (22). Parental dreams and aspirations for their child's future can be held in question when a chronic disease is identified. Therefore, the positive long term outcome for the overwhelming majority of affected children and adolescents must be emphasized frequently. Often there are strong feelings of anxiety, fear and guilt. As in many other chronic diseases afflicting pediatric patients, parental stresses can lead to aberrant behavior that can negatively impact on the child's lifestyle. Some parents react to their offspring's illness by excessive control, overindulgence or excessive restrictions on age-appropriate activities. Repeated reassurances that their child's illness has not occurred as a result of their actions or lack of intervention are essential. At the time of initial diagnosis many parents are very concerned that the time interval between the onset of clinical symptoms and diagnosis has been excessive and harmful for their child. Similar to the strategy for affected children, parental stresses and resulting maladaptive parenting skills are usually improved by factual education about the underlying intestinal disease. Similarly, self-help groups can provide additional factual information. They can also reduce parental feelings of isolation by providing a focus for interactions with people who live under similar stressful circumstances. In less responsive circumstances consultations with skilled medical social workers and psychiatrists can dramatically improve family dynamics.

\section{CONCLUSIONS}

In summary, the authors have attempted to provide support for the concept that consultative care of children and adolescents with both Crohn's disease and ulcerative colitis should promote a return to a normal, age-appropriate lifestyle. A focus on psychologic and social stresses and the reduction of restrictions in daily routines will help to realize this objective in the overwhelming majority of young patients.

Several reviews of IBD in the pediatric population support the role of a multidisciplinary health care team for optimal care $(11,12)$. The authors support this approach but acknowledge that easily designed short term and long term studies should be undertaken to document that there is, in reality, an improvement in patient morbidity and functional outcome with the use of what is an expensive and labour intensive approach to the provision of medical care (23).

\section{REFERENCES}

1. Kirschner BS. Inflammatory bowel disease in children. Pediatr Clin North Am 1988;35:189-208.

2. Levenstein S, Prantera C, Luzi C, D'Ubaldi A. Low residue or normal diet in Crohn's disease: A prospective controlled study in Italian patients. Gut 1985;26:989-93.

3. Michener WM, Wyllie R. Management of children and adolescents with inflammatory bowel disease. Med Clin North Am 1990;74:103-17.

4. Koletzko S, Sherman P, Corey M, Griffiths A, Smith C. Role of infant feeding practices in development of Crohn's disease in childhood. Br Med J 1989;298:1617-8.

5. Bennett WM, DeBroe ME. Analgesic nephropathy - A preventable renal dis- 
ease. N Engl J Med 1989;320:1269-71.

6. Bergstrand O, Hellers G. Breast-feeding during infancy in patients who later develop Crohn's disease. Scand J Gastroenterol 1983;18:903-6.

7. Whorwell PJ, Holdstock G, Whorwell GM, Wright R. Bottle feeding, early gastroenteritis and inflammatory bowel disease. Br Med J $1979 ; 278: 382$.

8. Gilat T, Hacohen D, Lilos P, Langman MJS. Childhood factors in ulcerative colitis and Crohn's disease. An international cooperative study. Scand ] Gastroenterol 1987;22:1009-24.

9. Hawkins C. Psychological problems and the management of patients with inflammatory bowel disease. In: Allan RN, Keighley MRB, Alexander-Williams J, Hawkins C, eds. Inflammatory Bowel Diseases. London: Churchill Livingstone, 1983:445-51.

10. Hamilton JR, Bruce GA, Abdourhaman M, Gall G. Inflammatory bowel disease in children and adolescents. Adv Pediatr 1979;26:311-41.
11. Lindquist BL, Järnerot $G$, Wickbom $G$. Clinical and epidemiological aspects of Crohn's disease in children and adolescents. Scand J Gastroenterol 1984;19:502-6.

12. Motil KJ, Grand RJ. Ulcerative colitis and Crohn's disease in children. Pediatr Rev 1987;9:109-20.

13. Bruce T. Emotional sequelae of chronic inflammatory bowel disease in children and adolescents. Clin Gastroenterol 1986;15:89-104.

14. Burke P, Meyer V, Kocochis S, et al. Depression and anxiety in pediatric inflammatory bowel disease and cystic fibrosis. J Am Acad Child Adolesc Psychiatry 1989;28:948-51.

15. Gazzard BG, Price HL, Libby GW, Dawson AM. The social toll of Crohn's disease. Br Med ] 1978;277:1117-9.

16. Schowalter JE. Psychological reactions to physical illness and hospitalization in adolescents: A survey. J Am Acad Child Psychiatry 1977;16:500-16.

17. Raymer D, Weininger $O$, Hamilton JR.
Psychological problems in children with abdominal pain. Lancet 1984;i:439-40.

18. Sorensen VZ, Olsen BG, Binder V. Life prospects and quality of life in patients with Crohn's disease. Gut 1987;28:382-5.

19. Hendriksen C, Binder V. Social prog nosis in patients with ulcerative colitis Br Med J 1980;281:581-3.

20. Carraccio CL, McCormick MC, Weller SC. Chronic disease: Effect of health cognition and health locus of control. J Pediatr 1987;110:982-7.

21. Schölmerich J, Sedlak P, Hoppe-Seyler $\mathrm{P}$, Gerok W. The information needs and fears of patients with inflammatory bowel disease. Hepatogastroenterology 1987;34:182-5.

22. Sabbath B. Understanding the impact of chronic childhood illness on families. Pediatr Clin North Am 1984;31:47-57.

23. Nolan T, Zvagulis I, Pless B. Controlled trial of social work in childhood chronic illness. Lancet 1987;ii:411-5. 


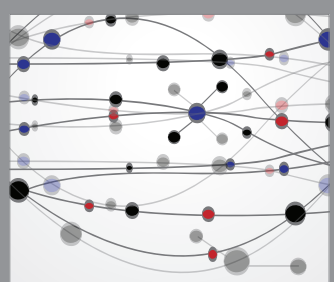

The Scientific World Journal
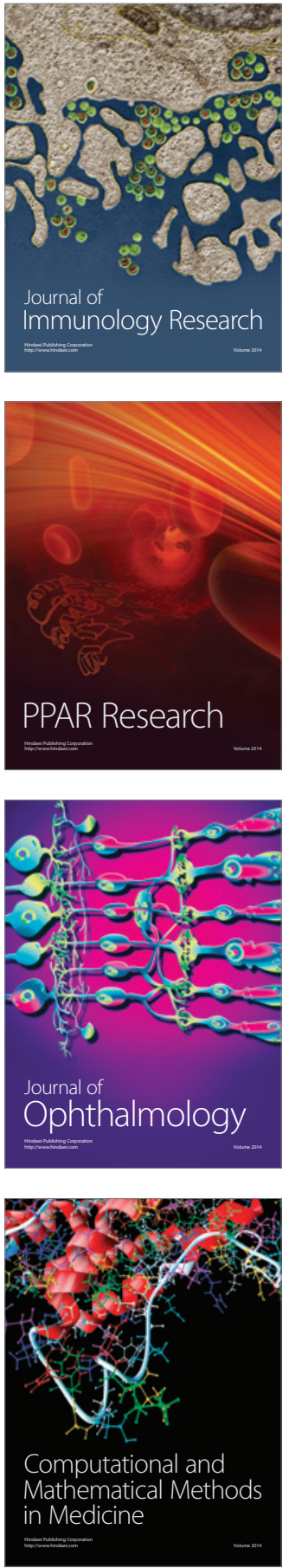

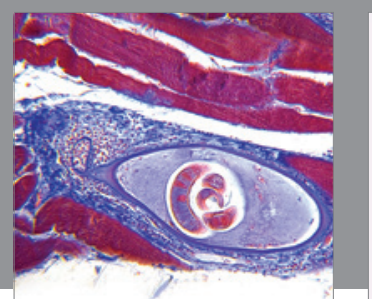

Gastroenterology Research and Practice

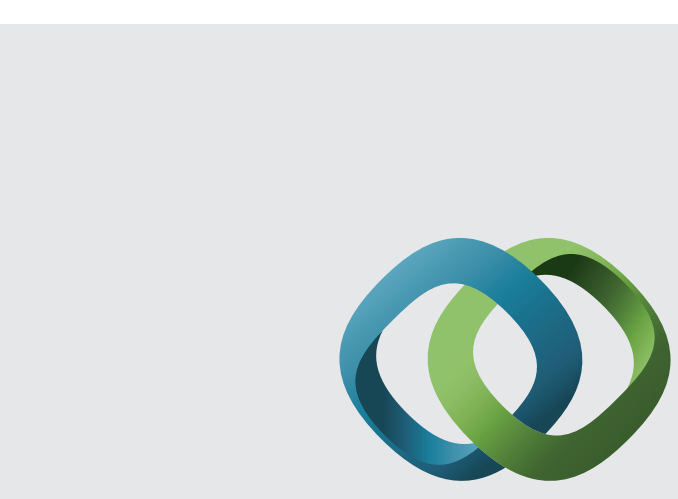

\section{Hindawi}

Submit your manuscripts at

http://www.hindawi.com
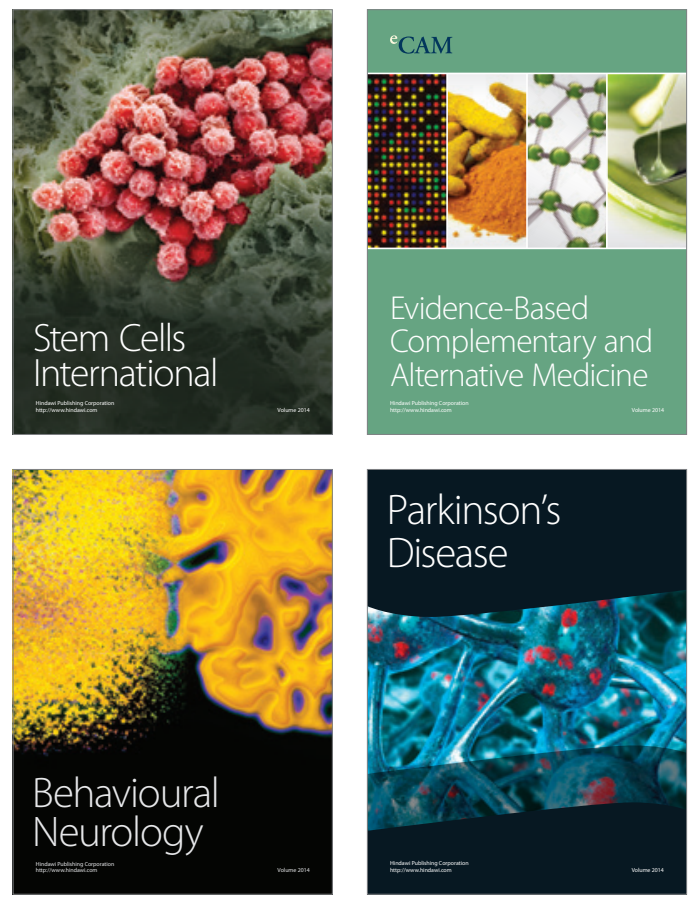
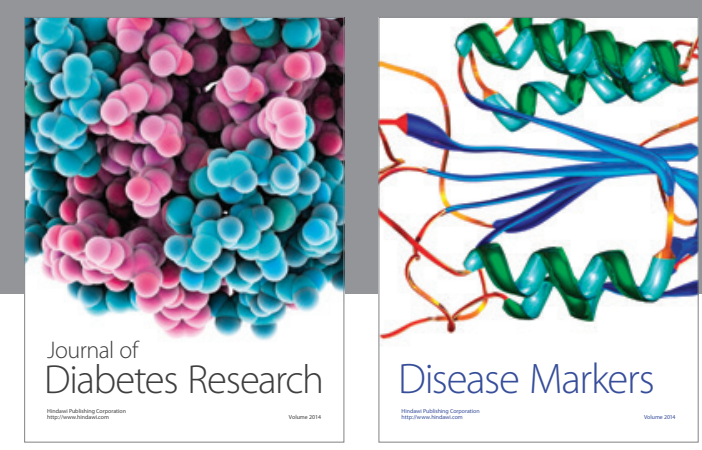

Disease Markers
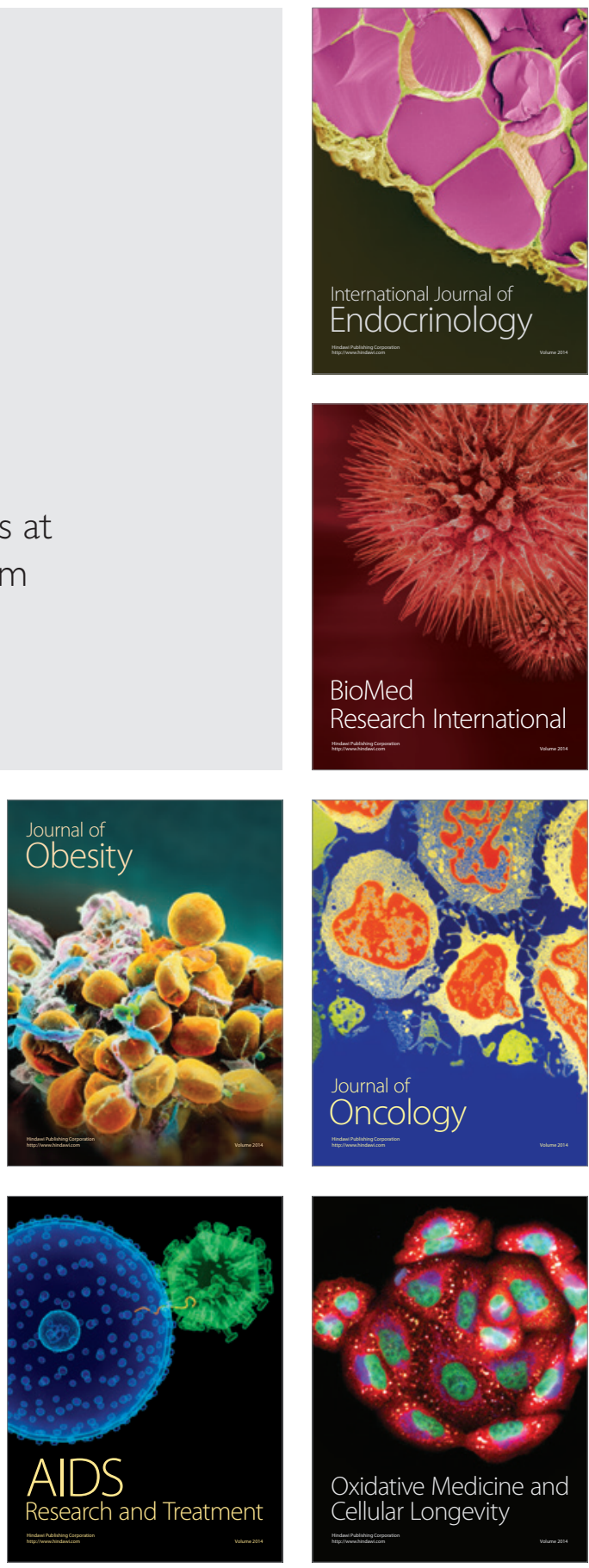